\title{
Chinese Dragons and Indigenous Tricksters: Lessons for Leadership through an Intersection of People, Culture, Thought, and Practice
}

\author{
William G. Lindsay \\ Simon Fraser University, Vancouver, Canada \\ Email: wlindsay@sfu.ca
}

How to cite this paper: Lindsay, W. G. (2018). Chinese Dragons and Indigenous Tricksters: Lessons for Leadership through an Intersection of People, Culture, Thought, and Practice. Creative Education, 9, 919-931. https://doi.org/10.4236/ce.2018.96067

Received: January 9, 2018

Accepted: May 13, 2018

Published: May 16, 2018

Copyright $\odot 2018$ by author and Scientific Research Publishing Inc. This work is licensed under the Creative Commons Attribution International License (CC BY 4.0).

http://creativecommons.org/licenses/by/4.0/

\section{(c) (i) Open Access}

\begin{abstract}
During the course of recent research, this author has discovered similarities between aspects of classical Chinese philosophies and practices of those of traditional Canadian First Nations (Indigenous) peoples. Included in this has been a discovery that aspects of traditional leadership skills from both cultures intersect and are applicable to the work happening in a modern Canadian university. The author has also personally observed an overlap in the culture and lives of Chinese and First Nations people in modern British Columbia, continuing a 150-year tradition in this part of Canada. This paper-tying aspects of these two cultural and historic threads together-will consider the questions: What fascinating observations can be made and what personal, philosophical, and leadership lessons can be contrasted and compared, learned and shared through this historic intersection of peoples, cultures, thoughts, and practices? And can these over-lapping examples assist in solving larger problems of identity in the modern world?
\end{abstract}

\section{Keywords}

Classical Chinese, Chinese, Chinese-Canadian, First Nations, Indians, Indigenous, Aboriginal, Canada, British Columbia, History, Culture, Interaction, Cedar and Bamboo, University, Philosophies, Leadership, Transformation, Blending, Medicine Wheel, The Seven Teachings, The Sages, Traditional Qualities, Mencius, Laozi, Tu Weiming, Dragons, Tricksters

\section{Shared History, Shared Experience}

The First Peoples of Canada shared much in common with the Chinese people who settled in this country. Even prior to the first recognized Chinese-First Nations contact in Canada, they shared common historical experience. The 
mid-1800s Chinese were victims of the importation and distribution of opium throughout their homeland. This British-backed trade, which came about as a result of the Opium Wars, caused irreparable harm to Chinese society in much the same way as the introduction of alcohol during the Canadian fur trade was to devastate First Nations people (Perdue, 2011; Ray, 1996). Lest observers think that the resultant addictions showed some kind of character flaw on the part of the Chinese and Canadian First Peoples, the introduction of crack cocaine and Chrystal meth to unsuspecting peoples of all backgrounds in modern times, allows people to see firsthand what happened in previous centuries when unknown addictive substances were introduced to unsuspecting societies.

As well, the introduction of Christianity, the imposition of colonialism, and the resultant rejection of traditional ways in Imperial China resulted in what one scholar has referred to as an "externally imposed and internally inflicted malaise" of the Chinese soul ( $\mathrm{Tu}, 1997)$. One only need exchange the words "China" and "Chinese" with "Canada" and "First Nations" and the common experience of peoples is again reiterated.

There are unsubstantiated rumors of Buddhist monks and early Chinese explorers visiting what became British Columbia, Canada in pre-European times (Clark \& McKay, 1992). But the earliest official interactions between Chinese and First Nations in Canada are highlighted in the sources below.

Although there was some initial contact in the late 1700 's, the history of First Nations-Chinese interaction really began in British Columbia in the mid-1800s. Lily Chow has written of First Nations-Chinese relationships and the numerous intermarriages that occurred between Chinese men and First Nations women in British Columbia during this time period. How these differing cultures and people helped one another, the resulting cross-cultural benefits, and how inter-cultural/inter-racial relationships developed during the eras of fur trade, railroad building, and gold rush are all explored by Chow (Chow, 2008).

Darren Friesen also explores the fur trade/gold rush times in British Columbia, including an examination of the local Stó:lõ people's interactions with early Chinese immigrants. Interestingly as inter-racial marriages took place, a social hierarchy emerged amongst this mixed marriage system which mirrored traditional Stó:lõ hierarchies (Friesen, 2006).

Christopher Herbert also examines the gold rush period in the mid-1800s Caribou region of what became British Columbia. In this time and place, inter-racial interactions were common. First Nations, Chinese, Caucasians, and African-Americans made up diverse communities, which in the hinter regions, collaborated in an inter-racial "we are all in this together" fashion-whilst, interestingly, the region's central town sites maintained strict segregation (Hebert, 2003).

In $20^{\text {th }}$ century Canada, through times of war and peace, depression and prosperity, the Chinese and First Peoples survived, sometimes thrived, but were 
often deprived as the country grew and changed. The unofficial segregation that existed in British Columbia at the time once again brought the Chinese and First Nations together in sometimes very unexpected and personal ways.

\section{A Writer's Personal Journey}

Older First Nations relatives and acquaintances who came of age in the 1940s and 50s have recalled to me a time when they and the Chinese were not allowed on the main decks of the BC ferries. They waited below, together, on the car decks. They remember, too, when mainstream cafés, in an accepted practice of the era, would not cater to "Indians" or Chinese. The only restaurants that fully welcomed First Nations people's patronage were Chinese.

During my own itinerant youth my family lived on different Indian reserves throughout the province. I always remember the eponymous Chinese cafes in nearby towns. I didn't particularly care for Chinese food at that time but when our family had money I always happily partook of the Western-style cuisine the Chinese became expert at preparing. I often wonder, in my educated older years, if these many cafés and their proximity to the local reserves were a by-product of the previous era when they alone catered to "Indians" and thus had large, nearby customer bases.

Once in a while my brothers and I went to off-reserve schools with the children of local Chinese. We had brown faces in common but they seemed to fit in better with a white world that was largely alien to me. They always seemed to do better in school, too. We never really hung out but for one brief six month stop-over in a northern community in 1974, Bill Wong was my best friend. His parents owned a local Chinese restaurant. I've never forgotten him.

When I was a "street kid" on Vancouver's gritty Eastside in the 1970s, Chinatown was in proximity to my 'hood. My crowd and theirs never mixed and mingled but we always seemed to have quiet respect for each other. I remember attending a local theatre-name long forgotten-that showed Chinese martial arts films with bad English subtitling. I still regret not taking lessons in Kung Fu instead of boxing at the local Native Friendship Centre.

The Vancouver area took on more of a Chinese character in the 1980s. A few complained but I didn't mind. Perhaps all those years crossing paths with the Chinese inadvertently had shaped my thoughts and non-prejudices. Later, I studied Chinese history in university, made Chinese friends, attended the local Chinese/Taiwanese film festivals, and found Chinese food to be my adult favorite.

A major personal turning point took place in 2001. A trip to China was followed-for professional and personal reasons-by a study of the Mandarin Chinese language, which has continued to this day. After years of on-and-off study and practice, and numerous follow-up trips to Asia, I have strangely become conversational in this most difficult of languages. I used to think I was perhaps unique in Canada: a First Nations person who could speak passable 
Chinese. However, at a 2008 conference I met a Mohawk chap who was also working at it. I now know there are at least two of us in Canada.

To this day, I am drawn to the Chinese people and their culture and customs almost as much as I am drawn to my own. This includes a love for Chinese food, music, movies, history, and use of chop sticks. As I am writing this paper, a Taiwanese student social event is taking place outside my university office. I wander out from time-to-time with interest and relish in understanding much of the Mandarin conversation taking place. Although not ethnically one of them, I feel drawn to them, a part of them.

I am First Nations to the core and fiercely defend Indigenous issues and people. I have now found myself doing the same for the Chinese. Recently, a patron in a Vancouver Chinatown restaurant starting spewing racial epithets towards the Chinese staff. I got up, went nose-to-nose, and told him to get out. He saw my size and serious intent and quickly left. Interestingly, another Native American patron stood up and joined me. Perhaps, we two native brothers shared similar history and experience with our Chinese friends. In retrospect I found myself asking who I had become. As I write this paper, I realize that I may be experiencing and feeling what some of my First Nations kinfolk experienced in the British Columbia of long ago.

The experience is reciprocal. My wife has become fluent in the Mandarin language and uses it-as I sometimes do-in assisting senior citizens and new immigrants, in translation work. Together, we provide a positive First Nations' face to our Chinese neighbors. This is one they are not used to seeing as many live amongst and directly see the many "native faces" that are part of the tough and troubled Downtown Eastside (DTES) community in Vancouver.

I recently had a young woman of Chinese heritage working in my Aboriginal-oriented university office. Her and I spoke Mandarin daily in the office and I also shared a few words of Cree. Interestingly, her perceptions of Aboriginal people beforehand were largely negative. This was based on media reports, common falsehoods/stereotypes, and, again, the perception of the DTES community. Yet, this young person willingly learned and worked so well with our people, that our office, with the participation of a First Nations elder, bestowed upon her the honor of a Native American name: "Acimosis", which in the Cree language means "Little Puppy". Conversely, I too have been honored with a traditional name by the local Chinese community for my work therein: 林伟力 (meaning "Magnificently Standing Forest"). The above employee has since moved to Hong Kong but not before remarking that she had come to perceive Aboriginal people as extremely successful. This is a remarkable change in thought, something made possible by cultural and workplace interaction. This is an excellent example of a contemporary First Nations-Chinese, cross-cultural synergy occurring, continuing a tradition that began in the 1800 's. This has happened to others, too, in modern times. 


\section{Finding Oneself: Cedar and Bamboo}

For example, the film Cedar and Bamboo explores the challenges of those with mixed First Nations-Chinese ethnicity in Vancouver, Canada. "What are you?" is a frequent question asked of these ones (Leung \& Todd, 2010). The film is full of revealing and unexpected insights. As an example, a young brother and sister bemoan the lack of knowledge from either side of their Chinese-Native heritage. They get asked the above question frequently. They want to fit in somewhere but as there is no specific Chinese/First Nations mixed-Métis-like-culture yet in existence, must they choose one side or the other? Or can they be among the first who can start a new and unique culture, based on a mixed Chinese-First Nations heritage? How multicultural and Canadian that would be!

In another case in the film, a mixed-blood/mixed-heritage First Nations elder born in British Columbia but raised in China, returns to Canada feeling like an immigrant in her place of birth. In spite of her background, it's still a surprise to Indigenous viewers when she suddenly bursts into fluent Cantonese. Reflecting on her life, she notes that it's been "complicated" having gone from her home community of Lil'wat, BC to Vancouver's Chinatown (Leung \& Todd, 2010).

In another interview, a man of mixed Chinese and Musqueam/First Nations descent, admits to knowing nothing of his Chinese heritage- "Who am I?" he asks, standing in the midst of Vancouver's Chinatown. Yet, he feels at home within the culture of the First Nation he grew up with (Leung \& Todd, 2010).

Not all the stories in Cedar and Bamboo are thus ones of "loss", of an identity crisis, or of wishing to "belong" somewhere. But it is a dominant theme. Ultimately, being taught to be a part of "something", to have a sense of belonging with a group, seems to make all the difference. While watching the film, I felt a powerful desire to reach out and tell those being interviewed to explore, seek, and educate yourself. If you need a world, get out there and find it, and enjoy the journey of exploration. I've been there: a mixed blood, First Nations-oriented, Chinese-speaking man, who once felt that he didn't belong anywhere. Now I feel privileged and secure to be actively associated with two worlds. This journey has been among the highlights of my now middle-aged life. And this personal cross-cultural experience has continued as the below experiences through work and education show.

\section{Worlds Compared, Worlds Combined}

It was with some fascination that I was able to find further analogies between Chinese and First Nation philosophies and strategies as part of my doctoral research. Specifically, a series of articles examining classical Chinese thought vis-à-vis my literature review discoveries which examined traditional Aboriginal thought and practice.

For example, the idea of a people "being at one with the earth" is a cross-cultural philosophy/praxis. On the First Nations side, many today characterize Native Americans as the first ecologists, as ones who lived "a virtuous life 
in harmony with the earth" (Sutton, 2004). Another text notes, that the First Nations of British Columbia "have an enduring relationship with the land, a bond so strong that it defines who they are" (Campbell, Menzies, \& Peacock, 2003). The idea of "Earth as mother" was prevalent in classical Chinese thought, as well. "Heaven is my father and earth is my mother...all things are my companions," wrote philosopher Zhang Zai in the 1020-1077 A.D. time period (Tu, 1997). Cross-cultural beliefs in animism are also manifest in the above thoughts and words.

In another instance, diviners in classical Chinese society would be directed through divine means to "withdraw from society, at least for a time...to interact more directly with the natural world" (Cheng, 1997). Such practice would not be unfamiliar to young First Nations men and woman, who temporarily withdrew from their traditional societies to pursue vision quests and menstrual/moon ceremonies, respectively (Zimmerman \& Molyneaux, 2000).

In a final example, The Shijing, or Book of Poetry, Book of Songs, and Book of Odes from ninth century China artistically depicts the everyday life of a typical Chinese community from that time. Poetic descriptions of religion, ritual, family life, and idealized leadership remind one that such mores, practices, and institutions are analogous across cultures and uncrossed oceans (Cheng, 1997). Such things were important to Canadian First Nations, too.

\section{Issues of Leadership}

Regarding the issue of leadership - which my doctoral research is focused on-concepts of Chinese classical thought and practice vis-à-vis traditional Indigenous ways of knowing and doing, also speaks to me across time and distance. The following chosen examples find resonance in my heart, mind, and experience.

EXAMPLE ONE: BLENDING

Roger T. Ames' paper "Contemporary Chinese Philosophy" emphasizes the blending of the traditional and the modern in contemporary China (Ames, 1997). This combination is seen as one way to update and strengthen a society that finds itself in a time of historic transformation.

In comparison, Aboriginal Affairs and Northern Development Canada described aspects of traditional Aboriginal leadership in People to People, Nation to Nation: Highlights from the Report of the Royal Commission on Aboriginal Peoples (1996). This section of the RCAP report explains the principles and methods of traditional Aboriginal leadership, particularly amongst First Nations, Dene, and Inuit societies. For example: hereditary systems, with emphasis on the cultivation of qualities amongst groomed leaders, and egalitarian systems, with emphasis on merit and special roles (Aboriginal Affairs and Northern Development Canada, 1996). The report thereafter explores the importance of consensus and accountability in its discussion of effective traditional leadership. The Aboriginal community expects to be informed and involved in decision-making 
processes. The report notes that although the Canadian Indian Act has eroded traditional leadership roles with its imposed election-style system, many elected leaders are choosing to work with traditional leaders in the governance of their communities (Aboriginal Affairs and Northern Development Canada, 1996). A mixture of the traditional and the modern is thus evident, with old and new being brought together to strengthen Aboriginal societies in a time of historic transformation.

In my role as a recognized Aboriginal leader, working in a modern university, I can relate to the above issues. Particularly, in the development of a leadership philosophy with combines the old with the new-albeit on a much smaller scale. This personal philosophy is explained and given context in my $\mathrm{PhD}$ literature review and concomitant synopsis paper, as follows:

1) If you are a leader, "lead".

2) Have a vision for the role/office.

3) Choose or develop a set of personal ethics to live by.

4) Consult as appropriate.

5) Make the tough decisions.

6) Have it as a goal to make most of the people happy, most of the time (Lindsay, 2015).

Points Three and Four I view as traditional skills needed for my current leadership position. Points One, Two, and Five I view as modern skills. Point Six is in-between. To explain, traditional First Nations leaders had culturally-honed ethical standards to live by and utilize-for example, The Seven Teachings and the Medicine Wheel (explained below). They also had to consult. These are important and needed traditional skills that are still requisite in modern times. But modern Aboriginal leaders still need to "lead", have a vision, and make tough decisions. These sound like modern corporate-type skills and they feel like such to someone like myself who has to utilize them. Finally, most traditional leaders had to have the support of the people en masse or they quit being followed as leaders. But in today's modern world, with larger constituencies, and with different agendas and jobs to deal with, having the support of the "most" is usually the best one can hope for.

EXAMPLE TWO: THE SAGES

In classical Chinese teachings, legendary sage-kings saw their prime responsibilities as:

1) Governing by persuasion;

2) Securing the welfare of the common people;

3) Maintaining the traditions of the ancestors;

4) Being frugal;

5) Seeing their position as a "trust";

6) Keeping harmony within the social order (Rosemont, 1997).

I can relate to this entire set of responsibilities from my current "Aboriginal" chair. With little money and no real authority beyond my office doors, I can only 
truly rely on persuasion to get things done; I have to think of students in my work, the common people if you will, as opposed to high-minded administrators and faculty; I have to always consider traditional practices and ways of doing things or people will question my Aboriginality; I have no choice but to be frugal (with a tiny budget); and I have to try like hell to keep harmony amidst diverse and demanding constituencies. Yes, I can indeed relate to the Chinese sage-kings, as per above...

I can also relate to the above concepts in a different way after having considered Kenny and Fraser's Living Indigenous Leadership: Native Narratives on Building Strong Communities (2012). The series of articles herein highlight the importance of effective Indigenous leadership and how certain leadership concepts are necessary components for improving Indigenous communities. The importance of cultural knowledge and values are highlighted throughout. Chapter three deals with the importance of traditional elders in a thriving community, providing a description of the qualities of elders, aspects of their teachings, and how the community benefits from their presence i.e. in the perpetuation of good life skills and cultural teachings (Kenny \& Fraser, 2012). Chapter fifteen invokes Anishinaabe beliefs regarding The Seven Teachings-courage, respect, honesty, humility, truth, love, and wisdom - and how these are used, in this case, to assist gang members to leave lives of crime and become community leaders (Kenny \& Fraser, 2012).

In my analysis the importance of Aboriginal elders-sages in this context-and their wise presence in Aboriginal communities is certainly applicable in academic institutions. This has certainly taken place, with universities throughout British Columbia having Elder's Programs situated therein. Elders bring a grandfatherly/grandmotherly presence to campus settings. They are cultural and familial treasures. They are also founts of experienced knowledge, providing guidance and direction to Aboriginal leaders wise enough to utilize such the result being, the wisdom of sage and king combined. The Seven Teachings are Anishinaabe in origin but they provide a cultural/spiritual skill set that can be used by effective Aboriginal leaders anywhere. They certainly describe the type of personal qualities that this Indigenous leader/servant chooses to utilize on the job at his university. The application of this set of values-for example, courage combined with respect and love when dealing with challenging situations and difficult people-along with a few other similar qualities, has never let him down. To be a so-called king is one thing; to tap into and emulate the wisdom of the sage is a more complex task but is certainly recommended.

\section{EXAMPLE THREE: QUALITIES}

The classical Chinese philosopher Mencius mentioned sympathy and empathy as key qualities needed for self-realization. He also listed the personal characteristics of someone who reached a stage of self-transcendence: goodness, truth, beauty, greatness, sageliness, and spirituality ( $\mathrm{Tu}, 1997)$. Such positive qualities bear resemblance to the Anishinaabe Seven Teachings, mentioned 
above-courage, respect, honesty, humility, truth, love, and wisdom-with which I am very familiar and which I utilize in my work. Also known in the First Nations world is the ceremonial use of sweet grass, with its emphasis on mind, body, and spirit; the Medicine Wheel with its holistic emphasis on the spiritual, emotional, mental, and physical aspects of a person's character; spiritual/ceremonial "medicine", which helps to maintain balance in relationships; and traditional "sweats" for purification (Belanger, 2010).

This brings to mind Julian, Wright, and Zinni's Songs from the Circle: Leadership Lessons Learned from Aboriginal Leaders (2009). The authors examine Aboriginal leadership vis-á-vis mainstream/Western concepts of leadership. Their research shows that Aboriginal leadership is guided to a greater extent by humility and spirituality (Julian, Wright, \& Zinni, 2009). Regarding spirituality, the application of Medicine Wheel teachings-balancing the physical, mental, spiritual, and emotional-and the skillful use of traditional storytelling are common traits associated with Aboriginal leadership (Julian, Wright, \& Zinni, 2009). Regarding humility, these researchers found that Aboriginal people usually frown upon being labeled "a leader". Rather, they view their role as being a "servant of the people", as someone stepping forward to fulfill traditional responsibilities (Julian, Wright, \& Zinni, 2009). This is similar to Confucian-Mencian ideals in which "service" to parents and society is valued and practiced (Tu, 1997).

I thought of the above when considering that a select few Aboriginal people have been designated as senior leaders in universities in British Columbia. These leaders generally view their role as a "responsibility" not as a title or command. In my experience, the very best Aboriginal institutional leaders see themselves as servants, partners, and engagers of the Indigenous community-students, staff, elders, and faculty-not avoiding them, as some do, surprisingly, to save time and energy and to avoid headaches. If one does not engage this community in this way, the standing of an effective leader is diminished, just as in traditional times when leaders were followed because they were respected. Effective leaders also bring aspects of spirituality and culture to their role. They might not call them Medicine Wheel teachings per se but aspects of various belief systems have similar components. The most effective leaders-those with credibility in the Aboriginal community-manifest aspects of traditional culture, teaching, and practice. Or at least they must be willing to learn such, if they have a history of assimilation/acculturation in their background. They don't have to be doing everything-"going totally native", so to speak-but they generally have to be doing something.

Jacqueline Ottman's work, First Nations Leadership and Spirituality within the Royal Commission on Aboriginal Peoples: A Saskatchewan Perspective (2002), also explores the issue of spirituality and its connection to First Nations leadership. The characteristics of First Nations leaders are explored, followed by an examination of the holistic nature of traditional leadership compared to 
Western leadership models.

The research shows that spirituality-in relation to healing and culture-is clearly a source of strength to Aboriginal leaders who want to be accountable, positive in outlook, trustworthy, and a source of inspiration to others (Ottman, 2002). For First Peoples, who have a holistic perspective on life, spirituality is something that makes up who they are, something that is "ingrained". It is not a part of life, it is life (Ottman, 2002). Spirituality includes believing in a Creator, being respectful of others, and cultivating such qualities as empathy, humility, patience, and love (Ottman, 2002). Spirituality is clearly an important aspect of a First Nations leadership model that aspires to be traditional in philosophy and practice.

Although specific to the First Nations of Saskatchewan, the principles highlighted within Ottman's research are certainly applicable to all First Peoples. This writer and university Director constantly asks himself how he can apply such qualities as empathy, humility, patience, love, and forgiveness on the job. These qualities, in this personal context, are not specific to Indigenous teachings but also to classical Chinese. Interestingly, the application of these and other "good" qualities has never let this particular Director down in his dealings with others.

\section{EXAMPLE FOUR: COMPLIANCE}

Not all of the comparative examples are positive. Tu Weiming-invoking classical philosopher Laozi-describes the negative traits that could be associated with traditional Daoist "non-action" philosophy: weakness, yieldingness, retreat, lostness, submission, and feebleness, to name some ( $\mathrm{Tu}, 1997)$. I relate to this in a rather unpleasant professional way, a feeling that was further enhanced during my $\mathrm{PhD}$ literature review.

For example, Dale Turner's This Is Not A Peace Pipe: Towards A Critical Indigenous Philosophy (2006) explores the challenge of creating a robust and critical Aboriginal intellectual community in resistant and hostile academic settings. An interesting interpretation of Turner's many assertions is the opinion that hostility can arise amongst Aboriginal staff in the academy when someone does little or nothing for his/her people when in a position to do so. Worse, this person may have assimilated into the mainstream culture (Turner, 2006). As universities are by nature colonial institutions, Aboriginal people imbedded therein can certainly become imbued with colonial attitudes.

It is my personal and professional experience that resistance and hostility can occur between Aboriginal individuals working in universities. Sometimes people get comfortable in cushy academic or staff positions. They don't like it when other Aboriginal people rock the boat. Issues of assimilation come into play, as do matters of professional envy and rivalry. Sometimes non-Indigenous supervisors have opposing and colonialist views concerning Aboriginal people and issues. Senior Aboriginal staff thus have to deal with the unsympathetic or opposing supervisor behind the other Aboriginal staff member-the latter feeling 
compelled to "toe the line". This can make for uneasy and awkward situations. But this does happen, perhaps to the surprise of those who think that Aboriginal people maintain a united "us against the world" stance.

How the Weiming-Laozi philosophy relates to this situation, is something unpleasant to contemplate and experience. Sometimes a strategic Aboriginal employee within an institution will follow a course of Daoist-like "inaction". The result is a yielding and submissive attitude to the dominant institutional culture. Such an employee ends up feeble, lost, and ineffective in the eyes of the Aboriginal constituency. Worse, they are observed being tough and vocal with their own people but not with the non-Aboriginal "other" that they should be.

\section{Dragons and Tricksters: A Finale}

The Chinese and First Nations people have proven resilient and adaptable through time. But in today's frantic and ever-changing modern world, they sometimes find themselves questioning their history, their place in the world, and a best way forward.

For First Nations people, questions constantly arise concerning culture, tradition, and modernity. For example, are traditional beliefs and practices still valid in the age of space travel, the computer, and modern education systems? In my experience, some will dogmatically state that traditional beliefs and practices will always be relevant. Others feel that only parts still matter. A select few feel that it all belongs in the past.

The Chinese face similar conundrums, in the wake of the Cultural Revolution and the end of the strict Maoist system. Philosopher Roger T. Ames discusses this, exploring the call for cultural reappraisal and renewal in modern China. Various ideas are propagated, including:

- Keeping a self-sufficient China isolated from Western culture;

- Rejecting Chinese traditions as unsuitable in the modern world;

- Combining Chinese and Western traditions to form a new hybrid tradition;

- Selecting and carrying over certain Chinese traditions to the modern setting, a process referred to as "selective inheritance" (Ames, 1997).

Hence, in the midst of a western-dominated and sometimes neo-colonialist world, First Nations and Chinese share a common, collective, and thoroughly modern experience. Major questions are: Who are we, where are we going as a people, and how should we get there?

Perhaps answers do lie in the past, ready to be reborn and utilized. In the traditional First Nations world, tricksters play a key cultural role. These spiritual beings are shape-shifters, mischief makers. They are able to transform themselves as needed for certain situations. Hence, they are also referred to as "transformers".

The BC First Nations Studies textbook states the following:

The trickster is a special, often very witty and humorous character ... he shows people the consequences of acting in an unacceptable manner. In a 
reverse way, the trickster is a moral, ethical, and philosophical teacher. Stories featuring the trickster often teach a moral lesson ... [The trickster] can take on the form of a human, an animal, or even the shape of an inanimate object such as a rock, stick, or tree ... trickster stories are often very funny. No one wants to be laughed at like the trickster so the stories act in a proactive, powerful way to prevent wrong-doing and uphold the law. A person in error can save face by listening to the story ... (Campbell, Menzies, \& Peacock, 2003)

The Chinese equivalent of the trickster may well be the dragon. Tu Weiming describes the dragon as "the mythic symbol of potency, creativity, and transformation" (Tu, 1997). It has the head of a tiger, the horns of a ram, the body of a snake, the claws of an eagle, and the scales of a fish. It's unlike any other living creature.

Hence, as a symbol of China, it is a "deliberate cultural construction" that indicates a "Chineseness" that derives from many sources (Tu, 1997).

The author of this paper sees himself-as might others, who are in this special place of cultural duality-as a mixture of trickster and dragon. Canadian First Peoples relate to the trickster character, with its wit and humor, its role as a teacher, the mischievous nature, the ability to transform, and the connection to the animal world. But some from this background can also relate to the dragon, a deliberate cultural construction, a Chinese mythological figure whose character and very sense of being derive from different sources. The dragon is a fascinating creature and is relatable to the cultural leanings of First Nations/Indigenous people who have been exposed to and are welcoming of Chinese ways into their lives. Trickster and dragon thus stand as symbols of transformation and power, thereby able to enhance the leadership skills of those influenced by the power of both beings and the cultures they come from, if one so chooses. Perhaps, all told, these cultural entities along with traditional teachings from long ago, can continue to provide answers to modern questions and bring comfort to societies, individuals, and institutions in states of flux.

\section{References}

Aboriginal Affairs and Northern Development Canada (1996). Traditional Leadership. People to People, Nation to Nation: Highlights from the Report of the Royal Commission on Aboriginal Peoples, 1. Ottawa: Minister of Supply and Services. http://olc.spsd.sk.ca/de/native30/unit2/leadership.html

Ames, R. (1997). Contemporary Chinese Philosophy. In E. Deutsch, \& R. Bontekoe (Eds.), A Companion to World Philosophies (pp. 520-522). Oxford, UK: Blackwell Publishers Ltd.

Belanger, Y. (2010). Ways of Knowing: An Introduction to Native Studies in Canada (pp. 300-301). Toronto: Nelson Education Ltd.

Campbell, K., Menzies, C., \& Peacock, B. (2003). B.C. First Nations Studies (pp. 16, 215-218). Victoria, Canada: British Columbia Ministry of Education. Vancouver, Canada: Pacific Educational Press, Faculty of Education, University of British Columbia.

Cheng, C.-Y. (1997). Reality and Divinity in Chinese Philosophy. In E. Deutsch, \& R. 
Bontekoe (Eds.), A Companion to World Philosophies (pp. 176-177). Oxford, UK: Blackwell Publishers Ltd.

Chow, L. (2008). Intermarriage between First Nations Women and the Early Chinese Immigrants to Canada: Case Studies in British Columbia, 1880-1950. In R. W. Heber (Ed.), Indigenous Education: Asial Pacific (pp. 345-358). Regina: Indigenous Studies Research Centre, First Nations University of Canada.

Clark, P., \& McKay, R. (1992). Canada Revisited: A Social and Political History of Canada to 1911 (p. 4). Edmonton, Alberta: Arnold Publishing Ltd.

Friesen, D. (2006). Canada's Other Newcomers: Aboriginal Interactions with People from the Pacific (pp. 69-81). Master of Arts Thesis. The College of Graduate Studies and Research, Department of History, University of Saskatchewan.

Hebert, C. (2003). Unequal Participants: Race and Space in the Interracial Interactions of the Cariboo Goldfields, 1860-1871 (Abstract 3). Master of Arts Thesis. Simon Fraser University.

Julian, M., Wright, B., \& Zinni, D. M. (2009). Songs from the Circle: Leadership Lessons Learned from Aboriginal Leaders. The Leadership Quarterly (pp. 6-10, 17-19). St. Catherines: Brock University, Canada.

Kenny, C., \& Fraser, T. N., Eds. (2012). Living Indigenous Leadership: Native Narratives on Building Strong Communities (pp. 48-63, 221-231). Vancouver: UBC Press.

Leung, D. E., \& Todd, K. (2010). Cedar and Bamboo. Documentary Film. Vancouver, British Columbia: Chinese Canadian Historical Society of B.C., Moving Images Distribution.

Lindsay, W. (2015). A Literature Review-Indigenizing the Academy through Indigenous Leadership: An Annotated Bibliography and Synthesis Paper (p. 36). Simon Fraser University: Directed Reading Project, EDUC 910-5, Supervisor: Dr. Kris Magnusson, Summer Session.

Ottman, J. (2002). First Nations Leadership and Spirituality within the Royal Commission on Aboriginal Peoples. A Saskatchewan Perspective (Abstract iii-iv, p. 8). MEd Thesis. Department of Educational Administration: University of Saskatchewan.

Perdue, P. (2011). The First Opium War: The Anglo-Chinese War of 1839-1842. Visualizing Cultures. 1. Massachusetts Institute of Technology. http://ocw.mit.edu/ans7870/21f/21f.027/opium_wars_01/ow1_essay01.html

Ray, A. (1996). I Have Lived Here Since the World Began (pp. 110-111). Toronto, Ontario: Lester Publishing.

Rosemont, H. (1997). Chinese Socio-Political Ideals. In E. Deutsch, \& R. Bontekoe (Eds.), A Companion to World Philosophies (p. 177). Oxford, UK: Blackwell Publishers Ltd.

Sutton, M. (2004). An Introduction to Native North America (2nd ed., p. 16). Boston, MA: Pearson Education, Inc.

Turner, D. (2006). This Is Not a Peace Pipe: Towards a Critical Indigenous Philosophy (p. 93, p. 177). Toronto: University of Toronto Press.

Tu, W. M. (1997). Chinese Philosophy: A Synoptic View. In E. Deutsch, \& R. Bontekoe (Eds.), A Companion to World Philosophies (p. 4, pp. 6-13, p. 20, p. 22). Oxford, UK: Blackwell Publishers Ltd.

Zimmerman, L. J., \& Molyneaux, B. L. (2000). Native North America (pp. 99-101). Norman, OK: University of Oklahoma Press. 